\title{
Infective endocarditis developing serious multiple complications
}

\author{
Selma Guler, ${ }^{1}$ Abdullah Sokmen, ${ }^{2}$ Bulent Mese, ${ }^{3}$ Orhan Bozoglan ${ }^{3}$
}

${ }^{1}$ Faculty of Medicine,

Kahramanmaraş Sütçü Imam University, Kahramanmaraș,

Turkey

${ }^{2}$ Department of Infectious

Diseases, Faculty of Medicine, Kahramanmaraș Sütçü Imam University, Kahramanmaraş, Turkey

${ }^{3}$ Department of Cardiovascular Surgery, Faculty of Medicine, Kahramanmaraş Sütçü Imam University, Kahramanmaraş, Turkey

\section{Correspondence to}

Dr Selma Guler,

selmaguler38@hotmail.com

\begin{tabular}{l}
\hline To cite: Guler S, Sokmen A, \\
Mese B, et al. BMJ Case \\
Reports Published online: \\
[please include Day Month \\
Year] doi:10.1136/bcr-2012- \\
008097 \\
\hline
\end{tabular}

\begin{abstract}
SUMMARY
A 20-year-old female patient with no history of heart disease presented to the hospital with high fever, cough and sputum. On the third day of hospitalisation, left facial paralysis developed and cranial revealed an infarct in the right frontoparietotemporal lobe. Transthoracic echocardiography revealed $1.5 \times 2 \mathrm{~cm}$-sized vegetation on the mitral valve and severe mitral regurgitation. On the 11th day of hospitalisation, multiple emboli were shown to be present in the left iliac artery. Since the patient had recurrent septic emboli despite 3 weeks of treatment, a surgical intervention was planned. The vegetation was removed and the mitral valve was replaced by mechanical prostheses. During the postoperative period, acute renal failure developed in the patient. The treatment was completed in 6 weeks with full recovery. This case confirms that infective endocarditis may present with various clinical situations, and that a high index of suspicion and surgical intervention, in addition to aggressive antibiotic therapy, is lifesaving.
\end{abstract}

\section{BACKGROUND}

Infective endocarditis (IE) is an acute or subacute endocardial infection caused by bacterial, viral or fungal microorganisms. It is associated with a high rate of mortality and morbidity in patients with anomalies of heart valves. The most common pathogens are Streptococcus viridans, which generally leads to subacute endocarditis, while Staphylococcus aureus causes acute endocarditis. Congestive heart failure and stroke are the relatively common and lifethreatening complications of IE. ${ }^{1}$ We report a case of an IE patient who presented with pneumonia and progressed with multiple septic emboli. The treatment was challenging due to multiple serious complications. Here, we wanted to highlight the importance of rapid diagnosis and appropriate treatment of IE to prevent serious complications.

\section{CASE PRESENTATION}

A 20-year-old female patient with no history of heart disease presented to the hospital with high fever, cough and sputum. After initial examinations, she was hospitalised with a diagnosis of pneumonia, and ceftriaxone $2 \times 1 \mathrm{~g} /$ day was initiated. On the third day of her hospitalisation, left facial paralysis had developed and the cranial CT revealed an infarct in the right fronto-parieto-temporal lobe (figure 1). The patient was referred to the department of cardiology with a suspicion of IE. Transthoracic echocardiography revealed a mass compatible with vegetation on the mitral valve measuring $1.5 \times 2 \mathrm{~cm}$ and severe mitral regurgitation. The vegetation was adherent to the atrial side of the mitral valve and measured $1.5 \times 1.9 \mathrm{~cm}$, and an eccentric jet flow of mitral regurgitation was detected on transoesophageal echocardiography (figure 2). The treatment was rearranged as ampicillin-sulbactam and gentamicin. The serial blood cultures were all negative. Since fever continued and no reduction in the size of the vegetation was observed, the treatment was replaced with cefepime $2 \times 1 \mathrm{~g} /$ day + vancomycin $2 \times 1 \mathrm{~g} /$ day. Since fungal infection could not be eliminated, amphotericin $B 50 \mathrm{mg} /$ day intravenous regimen was added to the treatment during follow-up. On the 11th day of hospitalisation, the patient suffered from an acute pain developing in her left leg, and on Doppler ultrasonography, the left iliac artery was shown to be occluded by an embolus. The patient was transferred to the department of cardiovascular surgery for embolectomy. Since the patient had recurrent septic emboli despite antibiotic treatment of 3 weeks duration without reduction in the size of the vegetation, a surgical intervention was planned (figure 3 ). The cultures of embolectomy material for bacterial or fungal growth were all negative. The vegetation was removed and replacement of the mitral valve by a mechanical prosthetic valve was performed. During the postoperative period, the vital signs remained stable with no high fever. However, acute renal failure developed in the second week of the postoperative period. Nephrotoxic agents were discontinued. The patient was treated by haemodialysis until the creatine levels returned to normal levels. The treatment was completed in 6 weeks, and she was discharged with full recovery.

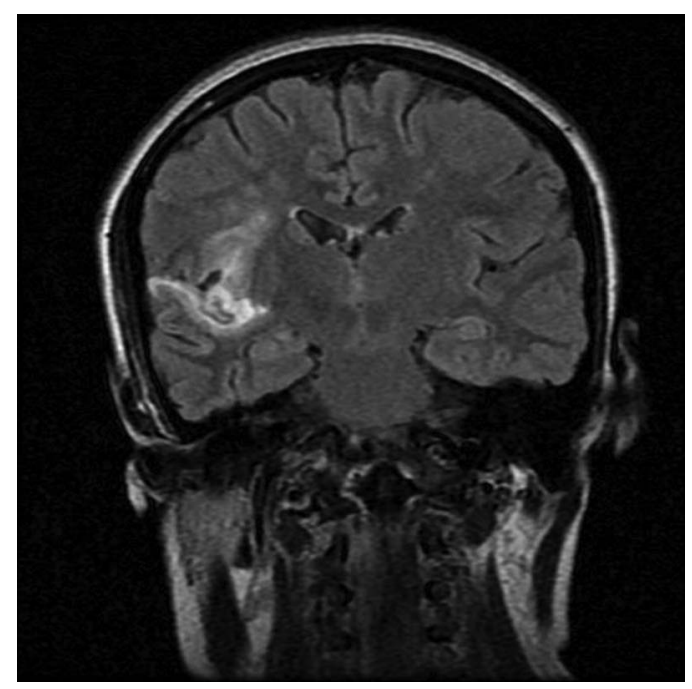

Figure 1 Magnetic resonance imaging. 


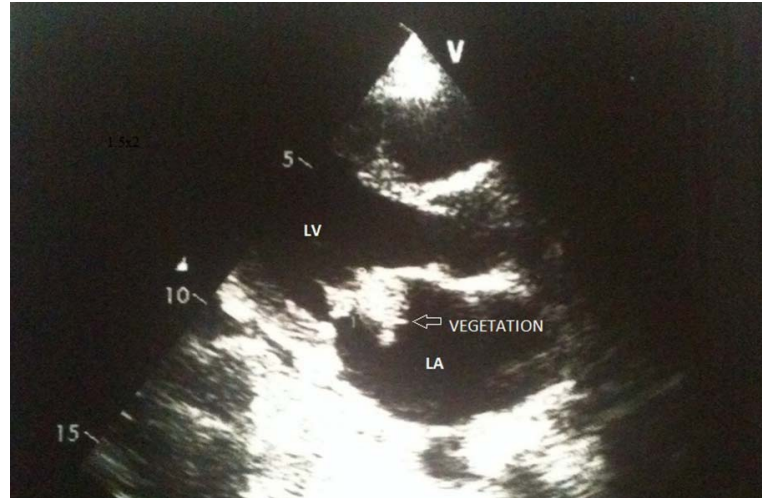

Figure 2 Transthoracic echocardiography image of vegetation. LA, left atrium; LV, left ventricle.

\section{INVESTIGATIONS}

- Basal non-contrast cranial CT

- $24 \mathrm{~h}$ control non-contrast cranial CT

- Transthoracic echocardiography

- Doppler ultrasound

\section{DIFFERENTIAL DIAGNOSIS}

- Pneumonia

- Cerebral infarction

- Arterial occlusion

\section{TREATMENT}

- Ampicillin, gentamicin

- Vancomycine, cefepime, amphotericin B

- Embolectomy in the left iliac artery

- Mitral valve replacement

\section{OUTCOME AND FOLLOW-UP}

She was discharged with full recovery.

\section{DISCUSSION}

Endocarditis may be classified as native valve endocarditis, endocarditis in intravenous drug addicts and prosthetic valve endocarditis. $^{2}$ The diagnosis of IE is based on a combination of fever, presence of vegetation in echocardiography and positive blood cultures. ${ }^{3}{ }^{4}$ Since a persistent low level of bacteraemia is found in patients with IE, the rate of negative blood culture is expected to be below 5\%. ${ }^{5}$ Although negative cultures may be associated

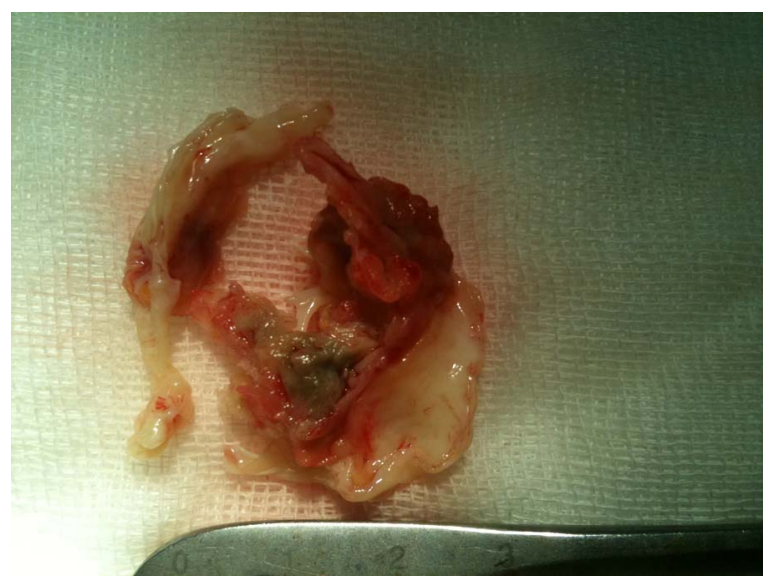

Figure 3 Postoperative image of vegetation. with a previous use of antibiotics, it may also be seen in fungal infections like Candida, Histoplasma and Aspergillus, and bacterial infections like Legionella, Coxiella and the HACEK group (Haemophilus species, Actinobacillus actinomycetemcomitans, Cardiobacterium hominis, Eikenella corrodens and Kingella kingae). ${ }^{67}$ In the current case, lack of growth in blood culture was associated with the previous intravenous administration of antibiotics; however, fungal infection was suspected during follow-up, based on the persistence of high fever; and empirical amphotericin B was added to the treatment regimen. Modified Duke criteria were developed using clinical and microbiological findings as well as findings in echocardiography. Systemic embolus is the most common complication of endocarditis involving major arteries and exerting a primary effect on the central nervous system. ${ }^{4} 5$ Despite appropriate antimicrobial treatment, neurological complications are found in $20-40 \%$ of patients. ${ }^{5}$ Embolic complications frequently develop during the initial stage of IE and prior to presenting to the hospital in particular. ${ }^{9}$ Fifty per cent of these cases occur within 20 days following initial symptoms of IE, while $80 \%$ develop within the first month. Following the initiation of antibiotic treatment, the risk of emboli is only $6-21 \% .^{4}$ Diameter of vegetation less than or equal to $15 \mathrm{~mm}$ and its motility, structure and rapid growth are major risk factors for emboli. Endocarditis caused by Staphylococcus, Candida species; HACEK and Abiotrophia have a higher risk of peripheral emboli. ${ }^{2}$ The risk of peripheral emboli is higher in mitral valve endocarditis than in aortic valve endocarditis. ${ }^{6}$ In our case, a vegetation of $1.5 \times 1.9 \mathrm{~cm}$ was found, causing cerebral emboli in the first week, followed by emboli in the iliac artery. Surgical intervention is a potentially lifesaving procedure for IE. Surgical treatment is required in 50\% of cases. ${ }^{5}$ Mortality and morbidity are associated with valvular regurgitation, heart failure, development of abscess and embolic complications. ${ }^{5}$ Early surgical treatment in IE may reduce the number of embolic episodes in future. ${ }^{3}$ However, it may lead to an increase in neurological symptoms in these patients during the acute phase of neurological events. Cardiac surgery is recommended after 2 4 weeks of optimal medical treatment in these cases. ${ }^{10}$ In the current case with recurrent emboli, the vegetation was removed and the mitral valve replacement was performed in the third week of the treatment. The combination of aggressive antibiotic administration and surgical intervention is life saving in these cases.

\section{Learning points}

- Infective endocarditis with large vegetations may cause severe complications that may be life-threatening.

- Previous antibiotic usage may lead to negative blood culture.

- Combined therapy including antibiotic regimen and surgery is necessary in complicated cases with multiple emboli.

Competing interests None.

Patient consent Obtained.

Provenance and peer review Not commissioned; externally peer reviewed.

\section{REFERENCES}

1 Turkkan D, Yuksel F, Samdanci E, et al. Enfektif Endokardite Bağli Santral Sinir Sitemi Septik Embolisi: Otopsi Olgu Sunumu. Inonu Universitesi Tip Fakultesi Dergisi 2010;17:387-9.

2 Priscilla J, Peters BA, RDCS, et al. Infective endocarditis. J Diagn Med Sonography 2005;21:162-203. 
3 Leblebicioglu $\mathrm{H}$, Yilmaz $\mathrm{H}$, Tasova $\mathrm{Y}$, et al. Characteristics and analysis of risk factors for mortality in infective endocarditis. Eur J Epidemiol 2006;21:25-31.

4 Kilic AU, Tutuncu E, Sari T, et al. Đnfektif Endokarditin Embolik Komplikasyonlari: Đki Olgu Sunumu ve Ulusal Literaturun irdelenmesi. Klimik dergisi 2011;24:179-83.

5 Baig W Wazir, Sandoe J. Infective endocarditis. Clin Med 2010;10:188-91.

6 Yasar KK, Pehlivanoglu F, Gursoy S, et al. Tricuspid endocarditis and septic pulmonary embolism in an intravenous drug user with advanced HIV infection. Oman Med J 2011;26:365-7.

7 Letaief A, Boughzala E, Kaabia N, et al. Epidemiology of infective endocarditis in Tunisia: a 10-year multicenter retrospective study. Int I Infect Dis 2007;11:430-3.
8 Kim GS, Kim JB, Jung SH, et al. Surgical management of infective endocarditis complicated by embolic stroke: early versus delayed surgery. Korean I Thorac Cardiovasc Surg 2011:44:332-7.

9 Rossi M, Gallo A, De Silva RJ, et al. What is the optimal timing for surgery in infective endocarditis with cerebrovascular complications? Interact Cardiovasc Thorac Surg 2012;14:72-80.

10 Fukuda W, Daitoku K, Minakawa M, et al. Infective endocarditis with cerebrovascular complications: timing of surgical intervention. Interact Cardiovasc Thorac Surg 2012;14:26-30

Copyright 2013 BMJ Publishing Group. All rights reserved. For permission to reuse any of this content visit http://group.bmj.com/group/rights-licensing/permissions.

BMJ Case Report Fellows may re-use this article for personal use and teaching without any further permission.

Become a Fellow of BMJ Case Reports today and you can:

- Submit as many cases as you like

- Enjoy fast sympathetic peer review and rapid publication of accepted articles

- Access all the published articles

- Re-use any of the published material for personal use and teaching without further permission

For information on Institutional Fellowships contact consortiasales@bmjgroup.com

Visit casereports.bmj.com for more articles like this and to become a Fellow 